\title{
BIOPOLÍTICA, VESTUÁRIO E TRANSGRESSÃO: ENSAIO SOBRE O VESTIR COMO INSTRUMENTO DE RESISTÊNCIA À HETERONORMATIVIDADE
}

\author{
BIOPOLITICS, CLOTHING AND TRANSGRESSION: ESSAY ON DRESSING AS AN \\ INSTRUMENT OF RESISTANCE TO HETERONORMATIVITY
}

\begin{abstract}
Lysia Maria Memória Viana ${ }^{1}$ e Felipe Albuquerque Sobral e Silva ${ }^{2}$
1 Universidade de Fortaleza, PPGA - Programa de Pós-graduação em Administração de Empresas, Brasil, e-mail: Iysiamviana@gmail.com, ORCID: https://orcid.org/0000-0002-7375-9558

2 Universidade de Fortaleza, PPGA - Programa de Pós-graduação em Administração de Empresas, Brasil, e-mail: felipesilva875@hotmail.com, ORCID: https://orcid.org/0000-0002-5708-1687
\end{abstract}

\author{
ART ICLE IN F O \\ Article history: \\ Received 2020-06-01 \\ Accepted 2020-11-30 \\ Available online 2020-11-30
}

Palavras-chave: Biopolítica. Sociedade de Controle. Corpo. Vestuário. Resistência.

Keywords: Biopolitics. Control Society. Body. Clothing. Resistance.

RESUMO. O presente estudo trata-se de um ensaio teórico que possui como objetivo discutir como ocorreu a marginalização dos gêneros alheios ao padrão binário através do conceito de biopolítica de Foucault, e como essa hegemonia pautada em mecanismos de dominação está sendo quebrada não só por meio de grandes movimentos e gestos, mas também por pequenos aspectos presentes no cotidiano desses indivíduos, sendo um deles a estética e, mais especificamente, o vestuário. O que se veste, portanto, assume o caráter de microrresistência e se torna um importante instrumento de identidade, liberdade, transgressão e transformação. Por se tratar de um ensaio teórico, o estudo é fundamentado na pesquisa bibliográfica acerca dos assuntos-chave, buscando uma compreensão mais aprofundada a respeito da relação entre poder, corpo, vestuário e sexualidade.

ABSTRACT. The present study is a theoretical essay that aims to discuss, through Foucault's concept of biopolitics, how the marginalization of genres outside the binary pattern occurred and how this hegemony based on mechanisms of domination is being broken not only through great movements and gestures, but also through small aspects present in the daily lives of these individuals: one of them is aesthetics and, more specifically, clothing. What someone wears, therefore, assumes the character of micro-resistance and becomes an important instrument of identity, freedom, transgression, and transformation. As this is a theoretical essay, the study is based on bibliographical research on the key issues, seeking a deeper understanding of the relationship between power, body, clothing, and sexuality.

\section{Introdução}

Tendo em vista que o sexo é um fator biológico definido ao acaso pela combinação cromossômica de dois indivíduos, e o gênero se trata de uma construção social, com base em Bakhtin (1986), entende-se que o gênero é um evento recorrente da atividade humana, que envolve papéis e relações sociais. Diante disto, ao longo dos anos, foram construídos padrões para serem socialmente aceitos, que procuraram excluir qualquer indivíduo que se 
identificasse com uma forma alheia à heteronormatividade e, na busca por ela, surgiram mecanismos sutis de controle que permearam todas as esferas sociais.

É diante desse contexto que se torna imperativo comentar quais as estratégias de dominação do aparato social sobre aqueles que não se enquadram no modelo normativo binário, excluindo e marginalizando a comunidade LGTBQIA+ (lésbicas, gays, bissexuais, travestis, transexuais, transgêneros, queers, interssex, agêneros, assexuados e mais), uma vez que todo e qualquer indivíduo que se enquadre nesses termos está, de alguma forma (ou várias), fora da regra.

Portanto, uma vez que essa marginalização sofrida pela diversidade de gênero foi construída a partir de processos culturais e discursivos, o objetivo deste ensaio é discutir como a diferença foi naturalizada - e não natural - por mecanismos estruturados com base nas relações de poder e dominação social explicados pelo conceito de biopolítica de Foucault, visa-se analisar como esse mecanismo está sendo quebrado por estratégias de sobrevivência e visibilidade por parte da comunidade, destacando entre elas a estética e, principalmente, a utilização do vestuário como um dos principais instrumentos de microrresistência, uma vez que ele é capaz de atuar na sociedade como um lugar de fala, libertação, transgressão e transformação social.

Por se tratar de um ensaio teórico, este trabalho é pautado na pesquisa bibliográfica, onde se buscou referências que tratem de temas-chave como biopolítica, comunidade LGBTQIA+ e o papel social da estética e do vestuário na contemporaneidade. Esta forma de discussão foi escolhida pois, de acordo com Barros e Lehfeld (2000, p. 78), "em termos gerais, são consideradas pesquisas teóricas aquelas que têm por finalidade o conhecer ou aprofundar conhecimentos e discussões"; e, de acordo com Tachizawa e Mendes (2006, p. 36), "a pesquisa teórica [...] busca, em geral, compreender ou proporcionar um espaço para discussão de um tema ou uma questão intrigante da realidade".

Para um melhor entendimento, este trabalho está dividido em quatro seções: a primeira se refere a esta introdução, na qual foram apresentados os pontos a serem discutidos, a justificativa e a natureza desta pesquisa; na segunda, tem-se a discussão a respeito dos temas propostos, onde se busca analisar o papel da biopolítica no controle da sexualidade; na terceira, é destacada a importância da estética e sua relação com os corpos indóceis na sociedade de controle contemporânea; e, por último, tem-se as considerações finais acerca da pesquisa, onde são apresentadas as conclusões a respeito da aplicação do vestuário como instrumento de transgressão do sistema binário instaurado, como ele vem sendo utilizado na quebra de paradigmas e, por fim, sugestões para futuras pesquisas relacionadas ao tema. 


\section{Fundamentação}

\subsection{A biopolítica no controle da sexualidade}

Atualmente, a realidade da comunidade LGTBQIA+ brasileira é pautada pela luta por seu espaço no meio social e na comunidade de direitos. Os indivíduos que se manifestam fora da classificação binária imposta, ao longo dos últimos anos, têm se organizado de forma a buscar acesso aos aspectos mais simples referentes à vida humana, como a inserção e permanência no mercado de trabalho, matrimônio e educação de qualidade, além de outras políticas públicas.

A discussão em torno de sexo, sexualidade, gênero e sua diversidade tem efervescido e ganhado bastante visibilidade nos últimos anos. Os movimentos sociais referentes a esses grupos têm alcançado alguns de seus objetivos, e as comunidades que compõem o amplo espectro da diversidade têm construído organizações monumentais com o intuito de fomentar a liberdade de expressão desses corpos e dar visibilidade às suas reivindicações. Apesar disso, o que ainda impera em muitas instituições e meios sociais é a imposição da normatividade heterossexual, deixando marginalizados os corpos cujas subjetividades não permeiam o gênero feminino ou masculino tradicional.

Esta imposição de regras normativas compõe uma complexa rede de micropoderes disciplinares, que visam a administração da vida e do próprio corpo social. Para Duarte (2008), Foucault evidencia, através de seus estudos referentes à sociedade de controle, que o próprio sexo se tornou um importante alvo da atuação dos mecanismos de poder.

Quando se pensa sobre os mecanismos de controle utilizados para regrar o indivíduo e a coletividade numa perspectiva social, torna-se quase imprescindível se falar sobre o corpo. Segundo Foucault (1987), os estudos sobre o corpo têm sido desenvolvidos no âmbito acadêmico há muito tempo, tratando-se por exemplo de demografia e processos biológicos. Contudo, eles possuem uma relação extremamente íntima - e bem óbvia, se uma ligeira reflexão sobre o assunto for feita - com o meio social e político. Para o autor, as relações de poder possuem atuação direta sobre os corpos, fabricando relações complexas de sujeição e produção. A sujeição não advém da violência, ao contrário do que muitos podem pensar: ela é pensada, calculada e instaurada da forma mais sutil, através de relações de controle que se encontram em instituições e aparelhagens, compondo o que ele chama de microfísica do poder.

Contudo, no evoluir de suas teorias e após sua análise dos dispositivos a respeito da produção da sexualidade, o autor passa a entender que, a partir de um certo momento na história, os mecanismos de poder já não objetivavam apenas disciplinar e tornar os sujeitos úteis socialmente, mas também normalizar e manipular fenômenos inerentes à vida humana (e, portanto, à própria vida) que não se restringiam mais apenas ao indivíduo, mas sim à população (DUARTE, 2008). O poder, portanto, além de buscar o controle sobre o sujeito 
singular e seu corpo dócil e útil, passou a buscar também a própria gestão da vida dentro do corpo social. É nessa perspectiva que nascem as concepções referentes à biopolítica: a biopolítica aqui, portanto, pode ser vista como uma tecnologia de poder que possui a capacidade de atuar nos corpos, tanto em termos de indivíduo quanto de população, para controlar e gerir as multiplicidades humanas (BUTLER, 2008; SANTOS, 2015). Diante disso, é comum se pensar neste controle sob um aspecto positivo, no qual se entende que o que se tem é uma série de interferências com o intuito de gerir e defender a população; mas não é bem assim. Sobre o assunto, Duarte (2008) complementa que:

\begin{abstract}
É justamente nesse ponto que a genialidade analítica de Foucault se evidencia: ali onde nosso sentido comum nos levaria a louvar o caráter humanitário de intervenções políticas que visam incentivar, proteger, estimular e administrar o regime e as condições vitais da população, ali mesmo nosso autor descobrirá a contrapartida sangrenta desta nova obsessão do poder pelo cuidado purificador da vida. Foucault compreendeu que, a partir do momento em que a vida passou a se constituir como elemento político por excelência, o qual tem de ser administrado, calculado, gerido, regrado e normalizado por política estatais, o que se observa não é uma diminuição da violência. (DUARTE, 2008, p. 4).
\end{abstract}

Portanto, se tratando de sexualidade e gênero, esse controle estabelecido pela biopolítica, por sua vez, implica a instauração de uma ordem sexual, onde se impõe sobre os corpos a necessidade de serem coerentes e de fazerem "sentido" através de um sexo e um gênero estável (BUTLER, 2008; SANTOS, 2015). O "poder que gere a vida" age sobre a sexualidade, e o controle da sexualidade atua na sociedade como uma prática regulatória.

Essa prática regulatória remonta ao século XVII, período no qual Foucault (1977), em História da Sexualidade (volume 1), afirma que se iniciou uma transformação dos assuntos ligados a sexo em práticas discursivas. Segundo o autor, essa época na sociedade cristã foi marcada pela instauração do rito da confissão dos pecados, principalmente os que se referiam aos prazeres da carne: tudo no sexo deveria ser transformado em discurso e confessado. Para Sierra (2013), esse alargamento das práticas discursivas produziu conhecimento a respeito do assunto - e conhecimento é poder. A repressão física propriamente dita não era eficiente para dominar os sujeitos, então foi preciso fabricar técnicas de observação comportamental e controle dos indivíduos através do chamado "dispositivo da sexualidade". A partir daí, os mecanismos de controle do sexo foram se tornando mais sofisticados e culminaram na aliança da confissão cristã à confissão em outros lugares, com o intuito de disciplinarização e correção: os consultórios médicos e os sofás dos analistas (SIERRA, 2013).

Neste sentido, para o autor supracitado, entende-se então que a biopolítica no controle da sexualidade descobriu seu poder no conhecimento a respeito dos comportamentos sexuais e assim desenvolveu mecanismos de controle e correção dos corpos considerados 
desviantes, por meio de processos de normalização que partiram de diversas instituições apoiadas em saberes psiquiátricos, médicos, pedagógicos e biológicos. Nos séculos que se seguiram (XIX e XX), a sexualidade seria medicalizada, e o foco do controle se voltaria às práticas contrárias às regras binárias, com o objetivo de restaurar o padrão normativo, ou o "instinto natural". A partir daí, essas práticas passam a ser entendidas como delinquência pela sociedade e como doença pelo discurso médico-psiquiátrico (SIERRA, 2013).

No século XXI, diante de muitas mudanças políticas, econômicas e sociais - que serão reservadas para um outro momento, pois fogem do objetivo do estudo - a comunidade LGBTQIA+ ganhou massa e voz. Apesar da sexualidade fora do padrão binário nunca ter sido e ainda não ser plenamente aceita na sociedade contemporânea, a partir de seus constructos de experiências e vivências políticas, sociais e psicológicas, a comunidade criou uma rede complexa de identificação social, de onde surgiu um movimento em massa que busca romper com a hegemonia reprodutiva, heterossexual e médico-jurídica nas mais diversas esferas da vida em sociedade.

A exposição das diferentes identificações no espectro da sexualidade tornou-se um ato político e um posicionamento diante da normatividade social imposta. A comunidade então se construiu sobre esses aspectos e pautou sua luta no reconhecimento e na defesa de suas sexualidades como legítimas. A militância da comunidade aos poucos tem conquistado o acesso e o direito a diversos aspectos que já são comuns há centenas de anos à heteronormatividade, ao mesmo tempo em que estão se inserindo também nos discursos políticos, econômicos, sociais, governamentais e, não menos importante, acadêmicos (BORTOLETTO, 2019).

\subsection{A estética e sua atuação nos corpos na sociedade de controle}

Apesar de alguns avanços terem sido conquistados pela comunidade LGBTQIA+ (e, diversos deles, muito recentemente), estas transformações não ocorreram "naturalmente". Pequenos aspectos da vida humana se apresentam como possibilidades de rompimento com o padrão imposto - "furos" que se constituem em pequenas lutas diárias para então se tornarem forma de resistência aos processos de normalização. A criminalização da homofobia, por exemplo, só foi possível após milhares de pessoas pertencentes à comunidade sofrerem diversos tipos de ataques, muitas vezes ao longo de toda a sua existência, em diversos casos culminando na perda da vida por este motivo.

Além disso, mais do que nessa camada visível de luta e conquista, existem formas de rompimento com a hegemonia também nas entrelinhas do cotidiano de cada sujeito inserido na comunidade, não importando seu grupo. Embora essa comunidade seja representada por uma sigla, os grupos que a compõem são inúmeros e extremamente heterogêneos.

Diante disso, a estética possui uma importância singular nesse quesito. Na visão de Bourdieu (2011, p. 56), a estética faz parte de um sistema que produz "condicionamentos 
sociais associados a uma classe particular de condições de existência", além de dar a possibilidade de o indivíduo expressar uma posição no espaço social. Portanto, as disposições estéticas acabam por se traduzirem em oportunidades de afirmação (e experimentação) da posição social que se quer ocupar, seja pelo distanciamento ou pela aproximação de um grupo social. Esse poder da estética de aglutinação e segmentação, então, se faz importante nesse quadro. Sobre o assunto, o autor infere que:

Como toda a espécie de gosto, ela (a disposição estética) une e separa: sendo o produto dos condicionamentos associados a uma classe particular de condições de existência, ela une todos aqueles que são o produto de condições semelhantes, mas distinguindo-os de todos os outros e a partir daquilo que tem de mais essencial, já que o gosto é o princípio de tudo o que se tem, pessoas e coisas, e de tudo o que se é para os outros, daquilo que serve de base para se classificar a si mesmo e pelo qual se é classificado. (BOURDIEU, 2011, p. 56).

Bourdieu afirma ainda que as preferências expressas através da estética são a manifestação das diferenças. Para ele, os gostos estão conectados à natureza do ser e, segundo Garcia (2008), essa conexão ocorre porque há uma interiorização do ser social pela personalidade. Esse sistema de gostos, então, se traduz em um grande veículo de significação, sendo parte do processo de organizar os comportamentos humanos e do próprio processo de transformação social na civilização contemporânea.

A personalidade formada nos indivíduos dos diferentes grupos sociais também influencia nas disposições estéticas. Assim como muitos outros aspectos, como a linguagem, a estética no âmbito da diversidade sexual foi se desenvolvendo ao longo do tempo como código de representatividade, lugar social e pertencimento a um determinado grupo, se tornando cada vez mais capaz de transmitir as várias mensagens acerca dos lugares desses indivíduos no mundo, através de uma grande produção simbólica.

Esta produção simbólica, hoje, está presente em tudo. "Classificados" por classes, gênero, região, idade, religião ou qualquer outro aspecto, os sujeitos fazem parte de comunidades onde existem meios sociais que possuem códigos próprios significativos e, onde há um meio social, há um conjunto de experiências, hábitos, valores, comportamentos, crenças e conhecimentos abarrotados de símbolos que são compartilhados por aquela população. Ou seja, há uma cultura.

Naturalmente, o próprio corpo e o que se põe sobre ele está inserido nessa perspectiva. Com o intuito de emitir um discurso, a estética pertencente aos grupos dessa comunidade, que não se encaixa no padrão heteronormativo, torna-se uma importante ferramenta de comunicação com a qual os corpos são capazes de construir imagens e de estruturar sua própria apresentação pessoal, revelando identidades e interferindo nos 
julgamentos, impressões e pensamentos da sociedade. Esta ideia pode ser reiterada pela perspectiva de Pereira e Ayrosa (2012), que afirmam que:

Para um certo grupo de gays, não é necessário apenas possuir um corpo musculoso, ter traços definidos e aparência jovem, mas também usar o corpo para reforçar perante a sociedade e os seus pares certo tipo de masculinidade. $O$ corpo desejado por esse grupo não é apenas o corpo do outro, mas o seu próprio corpo, pois o corpo desejado é espelho do seu, ou seja, um corpo de homem masculino, heterossexual e dominante. Ter um corpo com signos que reforcem esse tipo de masculinidade é resistir ao estigma que o desqualifica, pois o associa ao nãohomem, a quem transgride os papéis heteronormativos designados aos homens. Assim, uma forma de se resistir ao estereótipo seria a produção de um corpo que externalizasse toda a masculinidade do homem e distanciasse o gay do estereótipo de que ele é um pária entre o masculino e o feminino. Esse corpo produziria, de forma positiva, outra espécie de estigma constituído por uma descrição identitária que o diferencia de outros grupos gays. (PEREIRA; AYROSA, 2012, p. 267).

Portanto, o mundo social de que cada sujeito faz parte é capaz de reforçar os sistemas de significados associados a seus corpos (PEREIRA; AYROSA, 2012), onde cada um se entranha em seu entorno conforme seu tempo e espaço. Desta maneira, o corpo acaba por refletir o que acontece ao seu redor, assim como o que acontece ao seu redor se torna o próprio corpo. Neste sentido, um dos elementos mais fortes a externar isso através da estética talvez seja o vestuário. O que se coloca sobre o corpo, aliado às práticas de consumo, possui uma enorme significação e constitui um fenômeno social inerente a todas as civilizações: a moda. O que hoje é moda - que não deixa ser também uma forma de linguagem - assumiu na contemporaneidade a configuração de um sistema de comunicação no qual todos os indivíduos participam (STEFANI, 2005). Em um primeiro momento, é comum associar a moda a um sistema superficial e exploratório. Contudo, o vestuário também pode evidenciar fenômenos sociais muito mais complexos do que os que são vistos nas camadas mais aparentes. O que se coloca sobre o corpo detém significações em comum para grupos de indivíduos e faz parte de todo um sistema simbólico que possui uma profunda função social.

Inicialmente aparecendo como um mero dispositivo de proteção e manutenção do pudor, a competência cultural inerente à forma de se vestir de um grupo acabou indo além do simples trajar: o vestuário tornou-se uma das maiores produções culturais da sociedade, assim como um dos maiores símbolos das culturas e subculturas do século XXI. No caso da comunidade LGBTQIA+, muito mais do que apenas identidade (não que isso seja pouco), o vestuário assumiu o papel de instrumento possuidor de enorme capacidade de se traduzir em transgressão, libertação, representatividade e arte: o que no passado se tratava de uma demonstração silenciosa do comportamento social visto como o "correto" e o "padrão", na contemporaneidade grita por transformação. 


\subsection{0 vestuário na desconstrução e reconstrução dos paradigmas}

Pode-se inferir que tanto a roupa quanto o próprio ato de vestir-se estão intimamente ligados ao ethos do ser humano e a sua construção pessoal enquanto sujeito integrante da sociedade - neste caso, uma sociedade heteronormativa e binária. Portanto, o código estético e de vestimenta como uma forma de comunicação não-verbal está intimamente ligado a uma estrutura social, política e econômica retificada pelas classes dominantes que impõe suas normas e crenças às minorias. Sobre isso, Andrade (1990) afirma que

o comportamento humano é entendido como comunicação"; os códigos e convenções simbólicos compostos no interior da sociedade são denominados Cultura; as escolhas realizadas de acordo com a dinâmica social são determinadas por uma Ideologia; "a classe dominante numa sociedade é também 'a classe que possui o controle da emissão das mensagens verbais e não-verbais' da mesma sociedade. (ANDRADE, 1990, p. 7-13).

Apesar de o termo "identidade de gênero" só ter sido introduzido pelo psicanalista Robert Stoller no Congresso Psicanalítico de Estocolmo, em 1963, esse sistema binário de classificação é antigo e foi se desenvolvendo cada vez mais a partir de construções histórico-sociais, tendo nele grande participação do vestuário. Apesar do tempo, as demonstrações binárias ainda ocorrem na contemporaneidade em vários aspectos, inclusive na vestimenta. Por outro lado, as concepções de feminino e masculino também foram alteradas em muitos aspectos. Com a heterogeneidade de culturas, cada sociedade possui concepções diversificadas, dependentes da classe, religião, raça, idade e outros elementos caracterizadores de cada grupo, determinados histórica, linguística e socialmente, sendo constituídos e instituídos pelas múltiplas instâncias e relações sociais, instituições, símbolos, formas de organização social, discursos e doutrinas (LOURO, 1996). Naturalmente, podese entender que, no evoluir de um processo tão complexo, o vestuário esteve presente, se modificando conjuntamente e sofrendo influência de todos esses aspectos. Sobre isso, Köhler (1996) afirma que:

Para a humanidade, o vestir-se é pleno de um profundo significado, pois o espírito humano não apenas constrói seu próprio corpo como também cria as roupas que o vestem, ainda que, na maior parte dos casos, a criação e a confecção das roupas fique a cargo de outros. Homens e mulheres vestem-se de acordo com os preceitos desse grande desconhecido, o Espírito do Tempo. (KÖHLER, 1996, p. 57-58).

Portanto, assim como as sociedades são plurais, também deve-se considerar o gênero no seu caráter plural. Num contraponto ao paradigma hegemônico da heteronormatização binária, a liberdade sexual cada vez maior deu origem a temas como a homossexualidade e a androginia, acarretando o surgimento na moda, na década de 1920, do movimento 
andrógeno e assexual, ou unissex (CAMARGO, 2015). O termo "androginia" remonta as suas origens à junção de dois termos gregos - andros (a entidade masculina) e gynos (a entidade feminina). Este conceito sofreu várias alterações e interpretações ao longo da história, estando sempre associado a lendas e a mitos (GODINHO, 2012). Nomeadamente, o vestuário tornou-se uma forma de questionar os papéis que competiam a cada um dos gêneros. "As mulheres dedicavam-se a atividades masculinas, usando roupa supostamente masculinizada, enquanto o vestuário usado pelos homens os tornava mais femininos" (LEHNERT, 2007, p. 24). Segundo Ross (2012), com a evolução das subculturas e dos estilos gay, dá-se uma experimentação no vestuário masculino, sendo recriado por variadas marcas de moda. Com os movimentos dos direitos das mulheres e dos gays nas décadas de 1960 e 1970, os estereótipos do masculino e do feminino foram questionados, tornando a androginia uma palavra-chave no universo da moda e sendo manifestada de diversas maneiras.

No cenário atual, também existe uma tendência para o crescimento do conceito unissex ou, como é atualmente chamado, agênero. Segundo Hoang (2013), há um nicho de mercado interessado na compra desse tipo de vestuário, com tendência a crescer, mas difícil de determinar. No Brasil, por exemplo, existem diversas marcas que estão apostando neste conceito e inclusive surgindo a partir dele. Além disso, outras marcas e e-commerces já consolidados no mercado estão apontando para o mesmo caminho, desenvolvendo áreas específicas para a comercialização de peças agênero, como é o caso do Mercado Livre.

Além da moda agênero, há outras questões tão complexas quanto essa, como a fluidez de gênero, na qual o indivíduo pode transitar por todo o espectro da identidade, sem amarras ideológicas e sem lugar de parada.

Este e outros são alguns dos cenários da comunidade LGBTQIA+ em que o vestuário e a moda como fenômeno social assumem papéis muito mais complexos do que os contidos na "superfície". Assim, percebe-se cada vez mais uma sociedade na qual os gêneros se misturam, onde o gênero binário está se transformando e se reconstruindo. $O$ indivíduo passou a ter o livre arbítrio de vestir e utilizar o que o identifica, e não obrigatoriamente o que Ihe é imposto, sobretudo no que concerne à imposição de vestimentas relacionadas ao gênero sexual. Na contemporaneidade, não é mais possível fixar e determinar uma identidade de gênero apenas "na primeira olhada".

É neste intuito também que o consumo de itens de moda pelo público LGBT desempenha seu mais significativo papel social e deixa em segundo plano a ideia tradicional de necessidade e classe social, acabando por funcionar como uma ferramenta de mensuração para o estudo das práticas sociais e da construção das identidades de gênero. Há, nestes consumidores, os que querem se expressar, se libertar, afrontar ou transgredir (senão todas as opções anteriores). Diante disto, fica fácil perceber como "a moda é o fenômeno que melhor demonstra esta capacidade e necessidade de mudanças da sociedade, que é refletida no processo de consumo" (MIRANDA, 2008, p. 17). 
As performatividades são múltiplas e podem estar em maior ou menor concordância com o que se espera desses corpos. A moda, então, está engajada nesta modificação da cultura, como já o fez antes, estando ao lado dos novos movimentos identitários contra a limitação dos corpos e transformando-se por meio das diferenças. Seu caráter subversivo é, hoje, mais forte do que nunca, e se encontra em uma posição na qual é capaz de questionar e tensionar a própria lógica binária (homem-mulher, masculino-feminino, hetero-homo), ressignificar os corpos e os objetos e abrir caminho para novas transformações.

\section{Considerações finais}

O corpo, uma vez inserido na sociedade, se torna, ao mesmo tempo, componente e reflexo dela e do contexto no qual está inserido. A biopolítica, no que diz respeito ao controle desses corpos, atua como um mecanismo engenhoso de dominação, capaz de gerir a sociedade não só em questões como utilidade, disciplina e docilidade, mas operar sobre o direito à própria vida (com todos os significados que esta palavra pode carregar).

A marginalização da comunidade LGBTIQA+ é fruto da naturalização da heteronormatividade, o que culminou na necessidade de luta e resistência por parte desses indivíduos pela (sobre)vivência cotidiana. Ainda na contemporaneidade, essas pessoas são estigmatizadas e excluídas socialmente, e os estereótipos de gênero imperam e continuam sendo vistos e utilizados como justificativa para a não aceitação, a segregação e a violência. Diante desta "mancha" tão forte no meio social, os que não seguem a heteronormatividade desenvolveram estratégias de resistências e transgressão, a fim de quebrar os paradigmas estabelecidos referentes à sexualidade. Isso ocorre através de grandes movimentos, como a parada LGBT, protestos e exposições de casos de preconceito, mas também ocorre por meio de pequenos aspectos da vida cotidiana, como é o caso do vestuário.

Apesar de a indústria que o movimenta possuir muitos aspectos negativos, o vestuário também oferece a possibilidade de externar para a sociedade a mensagem que se quer transmitir, constituindo para a diversidade de gênero um instrumento de libertação, de auxiliar na manifestação do verdadeiro "eu" dos indivíduos (sendo ela estática ou fluida), de bater de frente com o considerado pela massa como "normal" e de resistir às normas impostas. Microrresistências como a apresentada neste estudo possuem um papel importante na transformação da sociedade e dispõem de todo um poder próprio. Gays, lésbicas, transgêneros, bissexuais, queers e tantas outras pessoas com outras denominações levantam todos os dias, se vestem e vivem suas vidas almejando as mesmas coisas que todos os outros, incluindo sentirem-se bem com o próprio corpo, a própria personalidade e as próprias escolhas. 
Contudo, é importante destacar que não se quer dizer com isso que o vestuário é uma espécie de "solução de problemas" quando as pessoas se utilizam dele, mas sim que ele pode se apresentar como um elemento capaz de auxiliar os indivíduos a assumirem suas verdadeiras formas, identidades, gostos e vontades, a ser quem eles realmente são.

Como sugestão para trabalhos futuros, propõe-se que seja realizado um estudo empírico das ideias aqui expostas, para que se possa explorar casos reais em que as roupas façam a diferença em algum desses aspectos, auxiliando na transgressão, na libertação, na representatividade e até mesmo na arte.

\section{Referências}

ANDRADE, A. M. M. S. Sob o signo da imagem: a produção da fotografia e o controle dos códigos de representação social da classe dominante, no Rio de Janeiro, na primeira metade do século XX. 1990. Tese (Doutorado) - Universidade Federal Fluminense, Niterói, Rio de Janeiro, 1990.

BAKHTIN, M. M. Speech genres and other late assays. Austin: University of Texas Press, 1986.

BARROS, A. J. S.; LEHFELD, N. A. S. Fundamentos de Metodologia: Um Guia para a Iniciação Científica. 2. ed. São Paulo: Makron Books, 2000.

BORTOLETTO, G. E. LGBTQIA+: identidade e alteridade na comunidade. São Paulo: USP, 2019.

BOURDIEU, Pierre. A Distinção: crítica social do julgamento. Porto Alegre: Zouk, 2011.

BUTLER, J. Problemas de gênero: feminismo e subversão da identidade. 2. ed. Rio de Janeiro: Civilização Brasileira, 2008.

CAMARGO, R. F. T. Moda e androginia nos anos 1920. In: Simpósio Nacional de História, 28, 2015, Florianópolis.

DUARTE, A. M. Sobre a biopolítica: de Foucault ao século XXI. Revista Cinética, v. 1, p. 116, 2008.

FOUCAULT, M. História da Sexualidade I: a vontade de saber. Tradução: M. T. C. Albuquerque e J. A. G. Albuquerque. Rio de Janeiro: Graal, 1977.

FOUCAULT, Michel. Vigiar e punir: história da violência nas prisões. Petrópolis: Editora Vozes, 1987.

GARCIA, A. N. Distinção social e processo civilizador em Norbert Elias. IARA - Revista de Moda, Cultura e Arte, São Paulo, v. 1, n. 1, 2008.

GODINHO, F. Trans como fenómeno de moda. Lisboa: Universidade Técnica de Lisboa, 2012. 
HOANG, L. Androgyny and minimalism to stalk London Fashion Week. Reuters, 13 fev. 2013. Disponível em: http://www.reuters.com/article/2013/02/13/us-fashion-britainpreviewidUSBRE91C1BD20130213. Acesso em: 1 nov. 2019.

KÖHLER, C. História do Vestuário. Tradução: Jefferson Luís Camargo. São Paulo: Martins Fontes, 1996.

LEHNERT, G. História da Moda do Século XX. São Paulo: Könemann, 2007.

LOURO, G. L. Nas redes do conceito de gênero. In: LOPES, M. J. et al. Gênero e Saúde. Porto Alegre: Artes Médicas, 1996.

MIRANDA, A. P. Consumo de moda: a relação objeto-pessoa. São Paulo: Estação das Letras e Cores, 2008.

PEREIRA, S. J. N.; AYROSA, E. A. T. Corpos consumidos: cultura de consumo gay carioca. Organizações \& Sociedade, v. 19, n. 61, 2012.

ROSS, F. Contemporary men's fashion and new technology: shifting perceptions of masculinity, menswear aesthetics and consumption. Fashion Colloquia, jan. 2012.

SANTOS, D. B. C. A biopolítica educacional e o governo de corpos transexuais e travestis. Cadernos de Pesquisa, Fundação Carlos Chagas, v. 45, n. 157, 2015.

SIERRA, J. C. Corpo, sexualidade e poder: a homossexualidade na mídia e as biopolíticas de prevenção contra a AIDS. Textura, Canoas, n. 28, p. 111-128, maio/ago. 2013.

STEFANI, P. S. Moda e comunicação: A indumentária como forma de expressão. Trabalho de conclusão de curso (Graduação em Comunicação Social) - Faculdade de Comunicação Social, Universidade Federal de Juiz de Fora, Minas Gerais, 2005.

TACHIZAWA, T.; MENDES, G. Como fazer monografia na prática. 12. ed. Rio de Janeiro: Editora FGV, 2006. 